\title{
A neural window on the emergence of cognition
}

Rhodri Cusack, ${ }^{1}$ Gareth Ball, ${ }^{2}$ Christopher D. Smyser, ${ }^{3}$ and Ghislaine Dehaene-Lambertz ${ }^{4}$

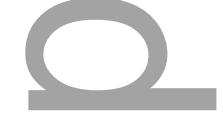

${ }^{1}$ Brain and Mind Institute, Western University, London, Ontario, Canada. ${ }^{2}$ Centre for the Developing Brain,' King's College London, London, United Kingdom. ${ }^{3}$ Departments of Neurology, Pediatrics and Radiology, Washington University, St Louis, Missouri. ${ }^{4}$ Cognitive Neuroimaging Unit, CEA DSV/I2BM, INSERM, CNRS, Université Paris-Sud, Université Paris-Saclay, NeuroSpin Center, Gif/Yvette, France

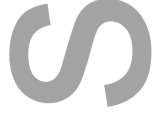

Address for correspondence: Rhodri Cusack, Brain and Mind Institute, Western University, London ON N6A1W8, Canada. rhodri@ cusacklab.org

Short title: The emergence of cognition

Abstract

Can babies think? A fundamental challenge for cognitive neuroscience is to answer when brain functions begin and in what form they first emerge. This is challenging with behavioral tasks, as it is difficult to communicate to an infant what a task requires, and motor function is impoverished, making execution of the appropriate response difficult. To circumvent these requirements, neuroimaging provides a complementary route for assessing the emergence of cognition. Starting from the prerequisites of cognitive function and building stepwise, we review when the cortex forms and when it becomes gyrated and regionally differentiated. We then discuss when white matter tracts mature and when functional brain networks arise. Finally, we assess the responsiveness of these brain systems to external events. We find that many cognitive systems are observed surprisingly early. Some emerge before birth, with activations in the frontal lobe even in the first months of gestation. These discoveries are changing our understanding of the nature of cognitive networks and their early function, transforming cognitive neuroscience, and opening new windows for education and investigation. Infant neuroimaging also has tremendous clinical potential, for both detecting

This is the author manuscript accepted for publication and has undergone full peer review but has not been through the copyediting, typesetting, pagination and proofreading process, which may lead to differences between this version and the Version of Record. Please cite this article as doi: 10.1111/nyas.13036.

This article is protected by copyright. All rights reserved. 
atypical development and facilitating earlier intervention. Finally, we discuss the key technical developments that are enabling this nascent field.

Keywords: cognition; neuroimaging; development; neonate; networks
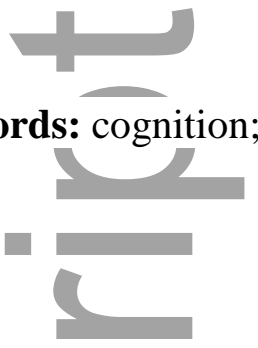

The poverty of the infant motor repertoire and the lack of evident voluntary actions led to the false impression that the infant's mental life was poor and empty or, in a contrary view, filled of a "blooming, buzzing confusion," yielding a similar disconnect with the external world. Yet, for the last several decades, developmental cognitive science has revealed particularly tantalizing glimpses into a surprisingly competent infant, as, at birth, neonates are able to recognize their native language, ${ }^{2}$ imitate adults' facial and gestural movements, ${ }^{3}$ and discriminate numbers. ${ }^{4}$ In addition, long before the end of the first year of life, infants rapidly develop social competencies, ${ }^{5}$ interpret actions in relation to an actor's goals, ${ }^{6}$ represent hidden objects, ${ }^{7}$ and display syntactic computations. ${ }^{8}$

However, identifying the age of emergence of many cognitive functions remains challenging. Young children find it difficult to understand what tasks require of them and to make appropriate responses. This limits the inference that is possible. A response to a task can provide evidence that a cognitive function is present, but there are many possible causes for an absence of a response, and an absent response does not imply that the cognitive function is absent. As a result, estimates of the emergence of many cognitive functions have been unstable, reducing substantially as new paradigms have been developed ((e.g., theory of mind (from 4 years in $2001^{9}$ to 6 months in 2010 ${ }^{10}$ ) and episodic memory (from 1-2 years in $1984^{11}$ to birth in $1994^{12}$ ). A complementary strategy for assessing cognition that can provide a rich additional source of information is the use of neuroimaging modalities, which do not require the infant to understand a task or make a purposeful response. Furthermore, this methodology provides access to the neural architecture and the changes that underlie human cognitive development, providing a crucial bridge to animal models and revealing what is shared or specific to humans. We focus here on prenatal and infant development. This nascent but growing field is fundamentally shifting our understanding of the ontogenesis of cognitive functions in the human brain.

We review evidence on the emergence of cognition from neuroimaging. Building stepwise from the foundations, we ask when the requisite cortical development takes place, when connecting tracts are formed, and when cortical networks begin functioning and processing information from the senses, followed by a synthesis of these steps. We aim to elucidate the main differences between humans and other primates before education and the cultural environment shape the infant brain. How different are the infant and adult brains? Can a better understanding of the neural architecture in children help to explain their prodigious learning capacities? We further assess the potential of neuroimaging to detect

This article is protected by copyright. All rights reserved. 
atypical development and review the methodological developments that have facilitated infant neuroimaging (Box 1).

\section{Neurogenesis and maturation of the cortex}

A fundamental prerequisite for the emergence of cognition is the growth of the cortex. Early in gestation, neurogenesis occurs in the ventricular zone and cells migrate radially along a glial scaffold towards the pial surface ${ }^{13}$ by mid-gestation, the cortical plate has appeared. Initially, cells in the cortical plate are oriented in a regular radial structure perpendicular to the pial surface. During the second and third trimesters, proliferative processes, synaptic formation, and dendritic arborization thicken the cortical plate, further delineating the cortical layers and transforming the cortical architecture from a radial arrangement into a complex and dense arrangement. ${ }^{14}$ Diffusion magnetic resonance imaging (dMRI) can provide access to these microstructural developmental processes in vivo by quantifying changes to the rate and principal direction of water diffusion within the cortex. The initial radial organization of the cytoarchitecture results in a larger relative fraction of water diffusion perpendicular to the cortical surface, indexed by fractional anisotropy (FA). With maturation, as the cortical plate begins to thicken and diversify, the movement of water becomes hindered equally in all directions until, by 40 weeks gestation, FA in the cortex is indistinguishable from zero. ${ }^{15,16}$ This process does not occur simultaneously across the cortex, but along a distinct developmental gradient. The rate of change in FA is significantly greater in the frontal, temporal, and parietal cortices during the third trimester, compared to the primary sensory cortex, where FA approaches zero by around 27 weeks gestation, ${ }^{15,17}$ demonstrating marked regional variations in cortical maturation that may reflect the borders of areal specialisation.

\section{Gyrification and the specialization of the cortical regions}

A critical component in the development of complex brain function is the differentiation of cortex into regions with specialized architecture and function. Regional brain function is associated with both the brain's microstructure (e.g., Brodmann's areas) and its macroanatomy, its sulci and gyri (e.g., the primary auditory cortex is found on Heschl's gyrus). It is thought that the formation of gyri and sulci is driven by the development of functional circuits, although there is controversy regarding the mechanism: axonal tension from white matter tracts, ${ }^{18}$ differential growth of the cortical layers within and across gray matter regions, ${ }^{19}$ or diffusion of morphogens. ${ }^{20}$ Gyrification is thus a marker of regional specialization, which can be quantified using MRI and provides further insight into patterns originally reported in postmortem histological studies. ${ }^{21,22}$ Cortical gray matter volume increases fourfold between 30 and 40 weeks gestation; ${ }^{23}$ this growth is achieved predominantly through an increase in surface area as the developing cortex begins to fold. Cortical gyrification follows a well-established developmental template: from around 14 weeks gestation, the primary sulci, including the Sylvian fissure, and the cingulate and parieto-occipital sulci begin to form, with secondary sulcation established by the normal time of birth. ${ }^{22}$ Despite individual variation, the spatial distribution of deep primary and secondary sulci are consistent and relatively stable after birth. ${ }^{21,24,25}$ In preterm neonates, sulci deepen dramatically between 25 and 35 weeks gestation. ${ }^{26}$ The macroanatomy of the brain is thus in many ways surprisingly mature by birth. Longitudinal MRI in healthy neonates has

This article is protected by copyright. All rights reserved. 
demonstrated that gyrification only increases modestly after birth (16\% in the first year and $6 \%$ in the second ${ }^{27}$ ), and that postnatal changes are predominantly in the heteromodal association cortex rather than the primary sensorimotor, auditory, and visual cortices. Recently, in utero examinations of fetal cortical development have mapped the nonlinear relationship between cortical curvature and age, with peak increases evident around 30 weeks that are largest in the posterior temporal and parietal lobes and lowest in the frontal, medial temporal, and cingulate cortices. ${ }^{28}$

As the cortical folding pattern is primarily established by the time of birth, it stands that sulcal development may represent an early anatomical marker of later functional specialization in the cortex. One such example is the developmental asymmetry of the superior temporal cortex, which is a specific human landmark. ${ }^{29}$ Postmortem evidence shows that the emergence of the superior temporal gyrus in the right hemisphere precedes the left by several days. ${ }^{22}$ Asymmetry in the perisylvian region is evident through the perinatal period in preterm neonates; ${ }^{30}$ has been closely charted in utero, ${ }^{31,32}$ and is present in healthy term-born infants, although it appears to evolve little in the following years. ${ }^{27}$ Interestingly, these structural asymmetries are observed in regions hosting important human cognitive functions (language on the left, social cognition on the right), elements of which are evident even at very early ages. ${ }^{33-36}$ suggesting that they represent an early foundation for the development of these functions in the brain. However, as a caution, it should be noted that structural and functional asymmetries do not appear to be tightly related.

\section{The development of structural connectivity}

The next prerequisite for effective cognitive functioning is the development of white matter connections between cortical regions and with the brain stem. The emergence of major axonal pathways from the basal forebrain and thalamus begins around 10 weeks gestation. ${ }^{37}$ Afferent projections extend towards the cortex and are initially organized within the subplate, a neural layer lying between the white matter and the cortex during development. ${ }^{38,39}$ It is a transitory layer, reaching maximum thickness between 22 and 34 weeks gestation. ${ }^{40}$

Structural MRI of healthy fetuses in utero during the early weeks of this period reveals a pattern of regional growth in the subplate that mirrors cortical development. ${ }^{41}$ During an initial "waiting period," the subplate is thickest beneath the developing primary somatosensory and auditory cortices, with substantial weekly growth also evident in the occipital region, but not the frontal subplate. In sensorimotor regions, the subplate begins to diminish at around 34 weeks, but it remains subjacent to the prefrontal cortex until around 6 postnatal months, a pattern reflecting the heterogeneous developmental timing of thalamoand corticocortical afferents arriving in each region. ${ }^{42,43}$

Thalamocortical afferents gather in the subplate from around 20 weeks, and the formative cingulum bundle is visible connecting the frontal and parietal regions from around 17 weeks. ${ }^{37}$ These large fiber systems are visible on MRI, and Takahashi et al. have provided a timeline for the development of cerebral and cerebellar connections from 17 to 40 weeks gestation using high-resolution postmortem fetal diffusion tensor imaging (DTI). After the regression of dominant radial cell migration pathways, ${ }^{44}$ long-range cortical association and projection tracts become visible at around $17-20$ weeks. ${ }^{37,45}$ After 24 weeks, short-range

This article is protected by copyright. All rights reserved. 
corticocortical pathways become apparent in parietal and frontal regions, resulting in the eventual formation of an adult-like pattern of connectivity by term. ${ }^{45,46}$ These observations have recently been replicated in healthy fetuses in utero. ${ }^{47}$

Axonal connectivity is intrinsically linked to cortical development. ${ }^{48}$ The concurrent and possibly complementary mechanisms of increasing axonal tension between connected regions and differential cortical layer expansion result in gyrification with increasing cortical volume. ${ }^{49-51}$ The linked developmental trajectory of anatomically connected structures is well documented and evidenced by the joint volumetric growth of connected structures over time or among populations. ${ }^{52}$ In preterm infants, total cortical volume is strongly correlated with both thalamic volume and the maturational state of the interconnecting projection fibers. ${ }^{53} \mathrm{In}$ healthy neonates, increases in cortical volume over the first 2-3 weeks of life, which are most prominent in frontotemporal regions, are synchronized with the micro- and macrostructural development of anatomically correspondent thalamic substructures. ${ }^{54}$ In a more direct assessment, Melbourne et al. ${ }^{55}$ used probabilistic diffusion tractography to trace corticocortical and corticospinal tract systems in a cohort of preterm infants. They found that the degree of connectivity (i.e., the number of connective stream lines terminating in the cortex) correlated with the amount of cortical sulcation in target regions, demonstrating a close relationship between white matter connectivity and cortical development that is established by the time of normal birth. ${ }^{55}$

The importance of thalamocortical connectivity in higher-order cognitive functions has been discussed extensively: thalamocortical connections project to the majority of the cortex in a set of parallel and segregated corticothalamic loops. ${ }^{56}$ Higher-order thalamic nuclei are thought to modulate corticocortical neural transmission via these loops, promoting interareal cortical integration and distribution of information across the cortex to support high-level cognitive functions. ${ }^{57,58}$ Therefore, it is likely that the perinatal development of the thalamocortical system will also affect higher-order function. Ball et al. explored this hypothesis in a cohort of preterm infants at term-equivalent age, using anisotropy along connective pathways as a surrogate marker for white matter development and structural connectivity in the thalamocortical system. ${ }^{59}$ In a combined model, incorporating gestational age at birth and parental socioeconomic status, thalamocortical connectivity in the neonatal period was found to be significantly associated with cognitive performance at 2 years of age. In adults, efficient information processing between brain regions relies on the integrity of white matter tracts; ${ }^{60}$ these data demonstrate that the perinatal period is crucial for the establishment of connective white matter tracts, with long-term impact if development or maturation is delayed or disrupted.

Beyond specific fiber systems, the structural organization of the brain can be conceptualized as a network, with graph theory providing a suite of quantitative metrics to describe both global and local topological network properties. ${ }^{61}$ In the adult brain, structural connectivity is centered on a set of highly connected hub regions, predominantly located in heteromodal association and thought to enable efficient information processing and support a diverse range of dynamic functional network configurations among connected regions. ${ }^{62,63}$ These "rich-club" regions display a high level of interconnectivity, forming a communication

This article is protected by copyright. All rights reserved. 
backbone in the brain ${ }^{64}$ comprising the frontal and parietal cortex, precuneus, cingulate, and the insula, as well as the hippocampus, thalamus, and putamen. ${ }^{62}$ Recently, studies have begun to investigate the development of structural connectivity during the perinatal period. Ball et al., found that many aspects of complex network architecture, including rich-club topology, were in place by 30 weeks gestation. ${ }^{65}$ Importantly, these structural networks were topologically similar to those observed in adults, with densely connected hubs present in the medial frontal and parietal cortex, precuneus, hippocampus, and insula. Between 30 and 40 weeks, connectivity increased between hub regions and the rest of the cortex in a manner compatible with the development of the rich club as a foundation for information transfer across the cerebral network. ${ }^{65}$ In a similar study, van de Heuvel et al. also demonstrated the stark similarities between neonatal and adult connectomes, revealing an $85 \%$ overlap of connections. ${ }^{66}$ Importantly, the development of structural connectivity, founded upon the development of large-scale white matter tracts during this period, also appeared to support the emergence of functional connectivity before the normal time of birth. ${ }^{66}$

Resting state networks

By term age, the cortex has acquired a complex laminar structure and has differentiated into distinct, specialized regions. Mature connective tracts have developed. The structural foundations, therefore, appear to be present for cortical networks to be functional. While it is known that structural and functional connectivity are interrelated, they are not identical. As such, which networks, if any, have begun to be active during each developmental period? This can be captured using resting-state functional magnetic resonance imaging (rs-fMRI), which measures spontaneous fluctuations in regional brain activity in the absence of stimulation or goal-directed activity. In adults, low-frequency fluctuations $(<0.1 \mathrm{~Hz})$ have revealed a number of canonical networks demonstrating synchronous, spontaneous neuronal activity, termed resting-state networks, ${ }^{67}$ associated with various cognitive functions and affected by neurological disease and cerebral injury. ${ }^{68}$

Beginning with Fransson and colleagues' description of five rudimentary networks in very preterm infants at term-equivalent postmenstrual age, ${ }^{69}$ use of rs-fMRI to study infant populations has expanded rapidly. ${ }^{70-85}$ Progressively younger subjects have been studied, including healthy, term-born infants and neonatal populations of clinical interest. Despite differences in populations and acquisition and analysis techniques, consistent patterns have emerged. Multiple canonical networks are present early in infancy. These comprise cortical, subcortical, and cerebellar regions and include networks incorporating primary motor and sensory cortices (e.g., somatomotor, visual, and auditory networks) and those involving association cortices (e.g., default mode, frontoparietal control, and dorsal attention networks) (Fig, 1). ${ }^{72,74,80,81,83}$ Many of these networks consist of strong interhemispheric connections between homotopic counterparts, with intrahemispheric correlations present but often quantifiably weaker. Early thalamocortical connectivity is also evident. ${ }^{72,83,86}$ The topology of these networks is similar in many ways to those obtained in adult and older pediatric populations. Importantly, recent investigations have suggested that rs-fMRI signal frequencies and select cortical and subcortical network measures relate to domain-specific neurodevelopmental outcomes during early childhood. ${ }^{87,88}$ In a longitudinal investigation,

This article is protected by copyright. All rights reserved. 
neonatal connectivity between the thalamus and salience network was related to working memory at 2 years of age. ${ }^{87}$ In the same cohort, spectral power in the motor and visual networks related to domain-specific performance at 1 year of age. ${ }^{88}$ The persistence of these relationships into middle childhood and the role of these and other networks in determination of normal and aberrant neurodevelopmental outcomes remains an area of ongoing investigation.

Studies in very early preterm infants and fetuses have found that these networks are identifiable early in gestation. ${ }^{72,83,89,90}$ Their development is shaped by the complex interplay between genetics, anatomy, endogenous activity, and external stimuli. The rate at which correlations within and between networks develop differs, reflecting the known rates of histological cortical and white matter development previously detailed. ${ }^{75,85}$ In these studies, networks incorporating primary motor and sensory areas (cortical regions known to mature early) are well established by term postmenstrual age, with topology and strength reflecting adult-like patterns. These networks demonstrate less variability between subjects. In contrast, higher-order networks incorporating heteromodal association cortices (later-developing regions) are also identifiable at term, though frequently in less complete forms. Alternatively, these networks mature gradually over the first years of life, reflecting known rates of cortical maturation. Further still, application of advanced analytic approaches, including graph theoretical methods and multivariate pattern analysis, reveals that these networks exhibit organizational features, including "small world" characteristics, comparable to those identified in assessments of structural connectivity.

It remains unclear how the early establishment of resting-state fMRI networks reflects the neurophysiological maturation of the cortex. Electroencephalography (EEG) recordings in preterm neonates are characterized by the existence of intermittent and focal bursts of activity, or spontaneous activity transients (SAT), the appearance of which appear to coincide with the formation of early circuitry in the subplate. ${ }^{40,91}$ During the third trimester, SATs begin to synchronize across hemispheres, and are eventually supplanted by continuous (albeit relatively low-frequency) EEG oscillations. ${ }^{92,93}$ In a recent study, Omidvarnia et al. ${ }^{94}$ demonstrated the reorganization of spontaneous events into spatially synchronous EEG networks that were present by term-equivalent age. That the developmental timelines of rsfMRI and EEG network synchrony are not coincident is perhaps unsurprising, given the differences in spatiotemporal sampling and driving neurophysiological processes of the two methods. However, it has been suggested that the early formation of fMRI resting-state networks (RSNs) is sensory driven and may subserve the formation of developmental circuitry that drives emergent EEG oscillations by the time of normal birth, ${ }^{95}$ possibly priming the brain for higher-order processing.

\section{Hello, world! Cognitive processing of sensory information}

At term, neurocognitive networks are structurally mature in many ways, and resting-state studies show they are functioning as a coherent network. Are they, however, receiving and processing information from the senses?

This article is protected by copyright. All rights reserved. 
During the last decade, functional brain imaging in infants has shaken two dogmas. First, contrary to the views of an initially equipotential brain, ${ }^{96,97}$ a complex functional organization is observed even in the fetal period, and the anatomical asymmetries already observed during fetal life have functional counterparts. A functional asymmetry at the level of the planum temporale is robustly observed with fMRI and near-infrared spectroscopy (NIRS) favoring the left side when stimuli with fast transitions are presented and the right side when the spectral dimension is predominant. ${ }^{98-104}$ This leftwards bias is selective and is not seen for all auditory stimuli. For example, activations are larger in the left planum for speech but symmetric for music within the same 3-month-old infant (Fig. 3). As in adults, these functional asymmetries appear to be context dependent, and Perani et al. ${ }^{102}$ reported a right advantage for music in their study where only music stimuli were presented, contrasting with the 3-month-olds' study in which two-thirds of the stimuli were speech, probably orienting the infants' attention toward the speech dimension. In experiments studying discrimination responses with event-related potentials (ERPs), a change of stimulus is suddenly introduced after several repetitions of the same stimulus. The mismatch responses have the same latency but a different topography for a change of voice and a change of phoneme. It suggests that the two features are coded in parallel by two different networks. ${ }^{105,106}$ Different mismatch responses are also observed in the case of visual changes concerning either the identity of the stimuli or their number. ${ }^{107}$ Models of the brain sources of these responses are congruent with the known brain areas involved in similar computations in adults. All these results demonstrate that the massively parallel organization of the adult neural architecture is a property observed in the brain from the first stages of cognition.

The second notable result revealed by brain imaging is the involvement of high-level regions in infants' cognition during the first months of life. Frontal areas that were previously assumed to be too immature to be functional in infants are repeatedly observed in fMRI studies. The RSNs comprise a frontal component from the fetal period on, ${ }^{72,83}$ and studies using stimulation reported robust activations in this lobe. It is not a general response of the whole lobe; distinct areas are involved depending on the task. When the verbal working memory is engaged, significant responses are measured in the inferior frontal regions, ${ }^{99}$ whereas longer-term memory of the prosodic contours of the native language appeals to the dorsolateral prefrontal region in relation to the inferior parietal region, locus of the phonological store in adults. ${ }^{98}$ Distinct responses to the mother's voice and to an unknown female voice are observed in the median prefrontal and orbitofrontal areas ${ }^{100}$ (Fig. 4); similar to activations to familiar/unfamiliar stimuli in adults. ${ }^{108}$ These observations challenge the classical view of a progressive organization and specialization of the brain from low-level to higher-level regions, but might support recent theories suggesting that abstract representations might accelerate learning ("the blessing of abstraction" ${ }^{109}$ ). However it is also possible that, when frontal activations are observed in infants, they may be at the end of a chain of connected regions without operational feedback on lower regions at an early age.

How do these architectures develop before term? Evoked response to auditory and visual stimulation have been recorded in fetuses and preterm infants from 6 months of gestation on, using magnetoencephalography (MEG), ${ }^{110-113}$ EEG, ${ }^{114,115}$ and MRI. ${ }^{116,117}$ As

This article is protected by copyright. All rights reserved. 
explained above, thalamocortical connectivity and the organization of the cortical layers are still far from the mature stage. Nevertheless, neural activity is already organized in structured networks with specific biases. For example, the discrimination of a consonant difference (/b/ versus /d/) activates a set of frontotemporal regions, comprising the left and right inferior frontal regions, whereas the perception of a change of voice (male versus female) was weak and mainly observed in the right inferior frontal region when NIRS was used in 30 week gestation preterm infants, ${ }^{106}$ (Fig. 5).

Preterm infants may react to external stimulation, but may not be ready to learn. Indeed, the loss of discrimination of foreign phonetic contrasts that classically occurs later in the first year of life depends on the maturational age and not on the duration of exposure to the ex utero environment. ${ }^{118,119}$ In other words, the developmental trajectory of preterm infants was not accelerated by their earlier exposure to speech and face-to-face exchange with their parents, ${ }^{119}$ suggesting that the external world does not influence the phonetic repertoire during the first weeks of life and thus that learning needs a more mature circuitry reached a few weeks later to stabilize and memorize the external world. ${ }^{120,121}$ Note that other capacities such as binocular perception, ${ }^{122}$ gaze following, ${ }^{123}$ or sensitivity to the phonotactic rules of the native language ${ }^{124}$ are advanced in healthy preterm infants relative to full-term infants, suggesting a different sensitivity to external stimulation between domains but also within a given processing pathway, owing to different tempos of maturation. ${ }^{121}$ These results underscore that, in order to evaluate neonatal care and preterm infant outcomes, it is necessary to precisely evaluate development in terms of cognitive systems and brain networks and not confine studies to general capacities as reflected by IQ. This approach is crucial in order to understand why preterm infants, even with no visible lesion and no risk factor beyond their preterm birth, nevertheless display a higher risk of cognitive deficits than full-term infants. ${ }^{125}$

If major structural and functional networks are in place from an early age, what is happening during development? The refinement of the microcircuitry through synaptogenesis and pruning, but also through the modulation of neurotransmitters, accompanied by an acceleration of the information transfer thanks to myelination, accelerates neural processing and improves their efficiency. Acceleration is certainly a crucial factor during the first year of age, easily seen with ERPs. The latency of the visual P1 increases from $300 \mathrm{~ms}$ at birth to 100 $\mathrm{ms}$ (the adult latency) around 12 weeks of life. This acceleration is correlated with a decrease in transverse diffusivity and an increase of fractional anisotropy, two markers of myelination, in the optical radiations. ${ }^{126}$ Note that myelination has two roles during development: the first aims at increasing speed, while the second maintain the same speed in a growing and thus larger brain. These two aspects are often mistaken when adults and infants are compared. By contrast, components reflecting higher levels of cognition remain slow. For example, the lateslow wave, which is speculated to be the infant equivalent of the P300, has a latency around $700-1000 \mathrm{~ms}$ after the stimulus, ${ }^{127,128}$ even at the end of the first year of life. These slow waves are usually elicited in functional paradigms in which attentional orientation, context memory, and conscious perception have been demonstrated. As maturation is not homogeneous across the brain, we may wonder how speed in different networks might affect

This article is protected by copyright. All rights reserved. 
infants' computations. In models of hierarchical predictive coding, ${ }^{109,129}$ faster computed representations may procure a gain relative to slower ones in order to update expectations in higher-level regions. Thus, it might be a productive approach to further consider the temporal dimension of the infant functional architecture. As the child is a prodigious learner, a better understanding of the dynamic properties of the infant neural architecture may help to develop new models of learning.

\section{The emergence of cognition}

Taken together, these converging results reveal that a rich set of neurocognitive functions emerge early in life, which was largely inaccessible to investigation before infant neuroimaging. Perhaps most surprising is the young age of maturation of neurocognitive networks of higher-level function. For example, by less than 6 months corrected age, ${ }^{a}$ the frontoparietal executive control network has developed a cortical laminar structure, developed cortico- and thalamocortical connections, begun functioning as a coherent network, and is selectively processing engaging stimuli from the environment.

Infants, of course, still have much to learn. But, what the neuroimaging evidence is suggesting is that this learning takes place within cognitive machinery that is already broadly structured in many ways like an adult's. As an analogy, an adult learning to tango may be enormously incompetent at the task to begin with. Given time, the necessary representations are pieced together, and expertise develops. However, this learning is considered to take place largely within existing neurocognitive networks and, at least at a broader scale, to leave them unchanged. This model of infant development challenges the conventional bottom-up view of cognitive development as a progressive involvement with age of higher-level regions, as well as the view of poorly specified initial networks that are progressively specialized through interactions with the environment. It suggests that the particular human brain architecture not only is a key factor in the cognitive successes of human adults but also provides a biological framework favoring learning from start.

This framework poses some intriguing questions. Why is this specific neural architecture efficient in learning? What are its computational properties? What are the limits of plasticity (e.g., after a lesion) and what variability of input (compared the sensory input of a fetus and of a preterm infant) is possible before cognitive development is impaired? If a three-month old infant has "executive function," what does this comprise, and why is it not more apparent behaviorally? The answer may lie in the cognitive demands placed by an unfamiliar world. Dual-task experiments have shown that adult executive function degrades when accompanied by a demanding second task, with even standing upright perceived as degrading when adults are given a demanding task. ${ }^{130}$ Given the infant's lack of expertise with the world, there are few environments that do not present a host of absorbing distractions. These implicit dual tasks would challenge any executive system, and may explain the lack of more apparent sophisticated executive behavior. Developing this idea further, infants are perhaps in even more need of executive function than adults. Given adults

${ }^{a}$ Past the expected date of full-term delivery.

This article is protected by copyright. All rights reserved. 
ability to recognize situations and recall learned associations, they can operate automatically in many ways, sometimes with little intervention from executive control (as any visitor to Las Vegas will testify). Infants, however, are presented continuously with an enormously complex puzzle, and must focus on what is important and piece the parts together. If anything, they are more in need of executive control. ${ }^{b}$

This framework is applicable to other cognitive domains, such as working memory and social cognition. Neuroimaging has provided evidence that, at a young age, these cognitive functions may have ignited. However, additional demands are placed on each system by a lack of knowledge: an inability to group items into chunks may increase working memory demands, and a lack of knowledge of social scenarios may constrain social cognition. Furthermore, the slowness of the information transfer may impair integration. For example, depending on the context, four-month-old infants remember the identity of objects or their localization, ${ }^{131}$ and integration of the features processed by the ventral and dorsal visual system is not realized before 12 years. ${ }^{132}$

To summarize, neuroimaging shows that many neural networks mature early. Finer neural tuning within these networks, including synaptic development and pruning, will then take place as learning proceeds. Going forward, the challenge will be to identify when different levels of representation develop within emerging cognitive systems. To address this, there is great potential in neuroimaging with multi-voxel pattern analysis methods ${ }^{133,134}$ to disentangle the emerging representational geometries within brain regions. ${ }^{135}$

\section{Potential of neuroimaging to detect atypical development}

Many infants are born very prematurely or sustain perinatal brain injury, which places them at higher risk of neurodevelopmental disorders. Early identification of the functional consequences of brain injury is important, so that interventions can be administered as soon as possible. However, early assessment is difficult owing to the limited behavioral and communicative repertoire of young infants. The current standard of care is largely to adopt a "wait and see" attitude - if there is functional damage, it will become apparent as the child develops. Unfortunately, by the time this happens, the windows of neural plasticity when interventions are most effective may have closed.

As the healthy trajectory of neurocognitive development begins to be better understood, there is increasing potential for neuroimaging to be used to detect atypical development. The many different kinds of neural measurement summarized in this review can be informative.

Taking prematurity as an example, many studies have attempted to quantify the relationship between early brain development, premature birth, and neurodevelopmental outcome. Increased mean diffusivity (an indicator of poor white matter organization and/or delayed maturation) in the central white matter at term-equivalent age is associated with lower developmental scores at 2 years of age. ${ }^{136}$ This association persists through early childhood

\footnotetext{
${ }^{b}$ And thanks to childhood amnesia, what happens in infancy stays in infancy.
}

This article is protected by copyright. All rights reserved. 
and into adolescence ${ }^{137-139}$ and appears to underlie, in part, the attentional deficits often seen in preterm children. ${ }^{140,141}$

In the cortex, fractional anisotropy in the cortex is linked to regional cortical growth, and both the rate of FA change in the cortex and the rate of cortical growth between 24 and 44 weeks have been shown to correlate with adverse developmental outcomes in early childhood. ${ }^{17,142}$ Cortical volumes are significantly reduced in preterm infants, particularly in the presence of the focal white matter injuries that can result in severe motor outcomes, such cerebral palsy. ${ }^{143-145}$ In the absence of such lesions, Boardman et al. ${ }^{146}$ described a composite phenotype comprising increasing white matter diffusivity and volume loss in the basal ganglia that was present in 66/80 preterm infants at term-equivalent age and predicted poor cognitive performance 2 years later. Coupled with recent evidence that the maturational state of thalamocortical tracts is also associated with poor cognitive outcome, ${ }^{147}$ this suggests that the linked disturbance of whole neural systems during early development has long-lasting functional implications. As an example of this, Bassi et al. ${ }^{148}$ used probabilistic tractography to delineate the developing optic radiations in a cohort of preterm infants at term-equivalent age. They found that fractional anisotropy (a marker of white matter development) within the tracts correlated with neonatal visual function. ${ }^{148} \mathrm{~A}$ second, longitudinal study that also included MRI scans from preterm infants as young as 25 weeks gestation found that visual function at term-equivalent age was best predicted by the rate of increase in FA between 30 and 40 weeks. ${ }^{149}$ This relationship between FA in the optic radiations and visual performance persists at least into the first year of life ${ }^{126}$ and likely beyond, demonstrating the importance of developing structural connectivity in the third trimester for later function.

Disruption to functional RSNs is also associated with altered neurodevelopment, and has been identified in a number of neuropsychological and neurodevelopmental disorders, including autism ${ }^{150}$ and attention deficit hyperactivity disorder. ${ }^{151}$ The effect of prematurity on network development is receiving increasing attention owing to the likely impact of preterm birth on early brain development. While conventional network mapping demonstrates similar topography and qualitative results between term and very preterm infants, ${ }^{69,72,83}$ quantitative measures have demonstrated that prematurity results in networkspecific reductions in network amplitude and complexity (Fig. 2). ${ }^{85}$ These disruptions persist through childhood. ${ }^{71,152,153}$ In addition, early RSNs are susceptible to environmental exposures, beginning as early as the fetal period. Recent investigations have related disruptions in networks incorporating the amygdala, insula, and varied cortical regions to maternal illicit substance use. ${ }^{154}$ Further longitudinal investigation remains necessary to define the role of disturbances in network configuration and strength due to these and other causes in the pathway to neurodevelopmental disability in high-risk neonatal populations.

Taken together, this evidence suggests that the failure to reach a prescribed maturational state by the time of normal birth may have a long-term impact on higher-level functions. We are, however, far from being able to predict neurodevelopmental outcome accurately on the basis of neuroimaging biomarkers alone. Genetic factors, other clinical factors, and/or environmental exposures affect early brain development. For example, recent reports suggest that variables, such as sex and socioeconomic status, may influence functional

This article is protected by copyright. All rights reserved. 
development in a network-specific manner. ${ }^{75}$ However, with rapidly improving neuroimaging technologies and advances in imaging healthy fetuses in utero, the ability to map these important processes precisely in vivo is improving. Combined with early studies of higherorder cognitive function, prevention of neural impairment will improve, and the window for early therapeutic intervention will hopefully become clearer.

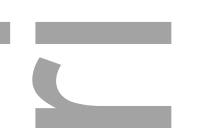

\section{Acknowledgments}

This work was supported by the National Institutes of Health (Grant Numbers K02 NS089852 and UL1 TR000448), the Cerebral Palsy International Research Foundation and the Dana Foundation, Fondation de France and Fondation Bettencourt (GDL), MRC (UK), NSERC/CIHR CHRP (201110CPG), NSERC Discovery (RGPIN/418293-2012), and the Canada Excellence Research Chair (CERC) in Cognitive Neuroimaging (RC).

\section{Conflicts of interest}

The authors declare no conflicts of interest.

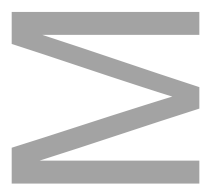

\section{References}

[1] W. James, The Principles of Psychology. New York: H. Holt and Company., 1890.

[2] J. Mehler, P. Jusczyk, G. Lambertz, N. Halsted, J. Bertoncini, and C. Amiel-Tison, “A precursor of language acquisition in young infants," Cognition, vol. 29, pp. 143-178, 1988.

[3] A. N. Meltzoff and M. K. Moore, "Imitation of Facial and Manual Gestures by Human Neonates," vol. 198, no. 4312, pp. 75-78, 2015.

[4] V. Izard, C. Sann, E. S. Spelke, and A. Streri, "Newborn infants perceive abstract numbers.," Proc. Natl. Acad. Sci. U. S. A., vol. 106, no. 25, pp. 10382-10385, 2009.

[5] J. K. Hamlin, K. Wynn, and P. Bloom, "Social evaluation by preverbal infants.," Nature, vol. 450, no. 7169, pp. 557-9, Nov. 2007.

[6] V. Southgate, M. H. Johnson, and G. Csibra, "Infants attribute goals even to biomechanically impossible actions," Cognition, vol. 107, no. 3, pp. 1059-1069, 2008.

[7] Y. Luo, R. Baillargeon, L. Brueckner, and Y. Munakata, "Reasoning about a hidden object after a delay: Evidence for robust representations in 5-month-old infants," Cognition, 2003.

This article is protected by copyright. All rights reserved. 
[8] A. Marquis and R. Shi, "Initial morphological learning in preverbal infants," Cognition, vol. 122, no. 1, pp. 61-66, 2012.

[9] H. M. Wellman, D. Cross, and J. Watson, "Meta-analysis of theory-of-mind development: the truth about false belief.," Child Dev., vol. 72, no. 3, pp. 655-684, 2001

[10] a. M. Kovacs, E. Teglas, and a. D. Endress, "The Social Sense: Susceptibility to Others' Beliefs in Human Infants and Adults," Science (80-. )., vol. 330, no. 6012, pp. $1830-1834,2010$.

[11] J. Bachevalier and M. Mishkin, "An early and a late developing system for learning and retention in infant monkeys," Behav. Neurosci., vol. 98, no. 5, p. 8, 1984.

[12] O. Pascalis and S. de Schonen, "Recognition memory in 3- to 4-day-old human neonates.," Neuroreport, vol. 5, no. 14, pp. 1721-4, Sep. 1994.

[13] P. Rakic, "Specification of Cerebral Cortical Areas," Science (80-. )., vol. 241, no. 4862, pp. 170-176, 1988.

[14] I. Bystron, C. Blakemore, and P. Rakic, "Development of the human cerebral cortex: Boulder Committee revisited," Nat. Rev., vol. 9, no. 2, pp. 110-122, 2008.

[15] H. Huang, T. Jeon, G. Sedmak, M. Pletikos, L. Vasung, X. Xu, P. Yarowsky, L. J. Richards, I. Kostović, N. Šestan, and S. Mori, "Coupling Diffusion Imaging with Histological and Gene Expression Analysis to Examine the Dynamics of Cortical Areas across the Fetal Period of Human Brain Development," Cereb. Cortex (New York, NY), vol. 23, no. 11, pp. 2620-2631, Nov. 2013.

[16] R. C. McKinstry, A. Mathur, J. H. Miller, A. Ozcan, A. Z. Snyder, G. L. Schefft, C. R. Almli, S. I. Shiran, T. E. Conturo, and J. J. Neil, "Radial organization of developing preterm human cerebral cortex revealed by non-invasive water diffusion anisotropy MRI.," Cereb. Cortex, vol. 12, no. 12, pp. 1237-1243, 2002.

[17] G. Ball, L. Srinivasan, P. Aljabar, S. J. Counsell, G. Durighel, J. V Hajnal, M. a Rutherford, and a D. Edwards, "Development of cortical microstructure in the preterm human brain.," Proc. Natl. Acad. Sci. U. S. A., vol. 110, no. 23, pp. 9541-6, Jun. 2013.

[18] D. Van Essen, "A tension-based theory of morphogenesis and compact wiring in the central nervous system.," NATURE-LONDON-, 1997.

[19] L. Ronan, N. Voets, C. Rua, A. Alexander-Bloch, M. Hough, C. Mackay, T. J. Crow, A. James, J. N. Giedd, and P. C. Fletcher, "Differential tangential expansion as a mechanism for cortical gyrification," Cereb. Cortex, vol. 24, no. 8, pp. 2219-2228, 2014.

[20] J. Lefèvre and J. Mangin, "A reaction-diffusion model of the human brain development," ... Imaging From Nano to Macro, 2010 ..., 2010.

[21] E. Armstrong, A. Schleicher, H. Omran, M. Curtis, and K. Zilles, "The Ontogeny of Human Gyrification," Cereb. Cortex, vol. 5, no. 1, pp. 56-63, Jan. 1995.

[22] J.G. Chi, E. C. Dooling, and F. H. Gilles, "Gyral development of the human brain," Ann. Neurol., vol. 1, no. 1, pp. 86-93, 1977.

[23] P. S. Hüppi, S. Warfield, R. Kikinis, P. D. Barnes, G. P. Zientara, F. a Jolesz, M. K. Tsuji, and J. J. Volpe, "Quantitative magnetic resonance imaging of brain development in premature and mature newborns.," Ann. Neurol., vol. 43, no. 2, pp. 224-235, 1998.

[24] Y. Meng, G. Li, W. Lin, J. H. Gilmore, and D. Shen, "Spatial distribution and

This article is protected by copyright. All rights reserved. 
longitudinal development of deep cortical sulcal landmarks in infants," Neuroimage, vol. 100, pp. 206-218, Oct. 2014.

[25] A. Raznahan, P. Shaw, F. Lalonde, and J. N. Giedd, "How Does Your Cortex Grow?," vol, 31, no. 19, pp. 7174-7177, 2011.

[26] J. Dubois, M. Benders, A. Cachia, F. Lazeyras, R. Ha-Vinh Leuchter, S. V. Sizonenko, C. Borradori-Tolsa, J. F. Mangin, and P. S. Huppi, "Mapping the early cortical folding process in the preterm newborn brain," Cereb. cortex (New York, N.Y. 1991), vol. 18, no. 6, pp. 1444-1454, 2008.

[27] G. Li, L. Wang, F. Shi, A. E. Lyall, W. Lin, J. H. Gilmore, and D. Shen, "Mapping Longitudinal Development of Local Cortical Gyrification in Infants from Birth to 2 Years of Age," J. Neurosci., vol. 34, no. 12, pp. 4228-4238, Mar. 2014.

[28] R. Wright, V. Kyriakopoulou, C. Ledig, M. a. Rutherford, J. V. Hajnal, D. Rueckert, and P. Aljabar, "Automatic quantification of normal cortical folding patterns from fetal brain MRI," Neuroimage, vol. 91, pp. 21-32, 2014.

[29] F. Leroy, Q. Cai, S. L. Bogart, J. Dubois, O. Coulon, K. Monzalvo, C. Fischer et al, "New human-specific brain landmark: The depth asymmetry of superior temporal sulcus,"PNAS, vol. 112, no. 4, 2014.

[30] J. Dubois, M. Benders, F. Lazeyras, C. Borradori-Tolsa, R. H.-V. Leuchter, J. F. Mangin, and P. S. Hüppi, "Structural asymmetries of perisylvian regions in the preterm newborn," Neuroimage, vol. 52, no. 1, pp. 32-42, Aug. 2010.

[31] P. A. Habas, J. A. Scott, A. Roosta, V. Rajagopalan, K. Kim, F. Rousseau, a J. Barkovich, O. a Glenn, and C. Studholme, "Early folding patterns and asymmetries of the normal human brain detected from in utero MRI.," Cereb. Cortex, vol. 22, no. 1, pp. 13-25, Jan. 2012.

[32] V. Rajagopalan, J. Scott, P. A. Habas, K. Kim, J. Corbett-Detig, F. Rousseau, A. J. Barkovich, O. A. Glenn, and C. Studholme, "Local tissue growth patterns underlying normal fetal human brain gyrification quantified in utero," J. Neurosci. Off. J. Soc. Neurosci., vol. 31, no. 8, pp. 2878-2887, Feb. 2011.

[33] G. Dehaene-Lambertz, L. Hertz-Pannier, J. Dubois, S. Mériaux, A. Roche, M. Sigman, and S. Dehaene, "Functional organization of perisylvian activation during presentation of sentences in preverbal infants," Proc. Natl. Acad. Sci. U. S. A., vol. 103, no. 38, pp. 14240-14245, Sep. 2006.

[34] H. Glasel, F. Leroy, J. Dubois, L. Hertz-Pannier, J. F. Mangin, and G. DehaeneLambertz, "A robust cerebral asymmetry in the infant brain: The rightward superior temporal sulcus.," Neuroimage, vol. 58, no. 3, pp. 716-723, Jun. 2011.

[35] F. Leroy, H. Glasel, J. Dubois, L. Hertz-Pannier, B. Thirion, J.-F. Mangin, and G. Dehaene-Lambertz, "Early maturation of the linguistic dorsal pathway in human infants.," J. Neurosci., vol. 31, no. 4, pp. 1500-6, Jan. 2011.

[36] M. Mahmoudzadeh, G. Dehaene-Lambertz, M. Fournier, G. Kongolo, S. Goudjil, J. Dubois, R. Grebe, and F. Wallois, "Syllabic discrimination in premature human infants prior to complete formation of cortical layers.," Proc. Natl. Acad. Sci. U. S. A., vol. 110, no. 12, pp. 4846-51, Mar. 2013.

[37] L. Vasung, H. Huang, N. Jovanov-Milošević, M. Pletikos, S. Mori, and I. Kostović, "Development of axonal pathways in the human fetal fronto-limbic brain: histochemical characterization and diffusion tensor imaging," J. Anat., vol. 217, no. 4,

This article is protected by copyright. All rights reserved. 
pp. 400-417, 2010.

[38] K. L. Allendoerfer and C. J. Shatz, "The subplate, a transient neocortical structure: its role in the development of connections between thalamus and cortex.," Annu. Rev. Neurosci., vol. 17, pp. 185-218, Jan. 1994.

[39] I. Kostović and N. Jovanov-Milosević, "The development of cerebral connections during the first 20-45 weeks' gestation.," Semin. Fetal Neonatal Med., vol. 11, no. 6, pp. 415-22, Dec. 2006.

[40] I. Kostović and M. Judas, "The development of the subplate and thalamocortical connections in the human foetal brain.," Acta Paediatr., vol. 99, no. 8, pp. 1119-27, Aug. 2010.

[41] J. Corbett-Detig, P. a Habas, J. a Scott, K. Kim, V. Rajagopalan, P. S. McQuillen, a J. Barkovich, O. a Glenn, and C. Studholme, "3D global and regional patterns of human fetal subplate growth determined in utero.," Brain Struct. Funct., vol. 215, no. 3-4, pp. 255-63, Jan. 2011.

[42] I. Kostovic, "Structural and histochemical reorganization of the human prefrontal cortex during perinatal and postnatal life," Prog. Brain Res., vol. 85, pp. 223-39; discussion 239-40, 1990.

[43] I. Kostovic and M. Judas, "The development of the subplate and thalamocortical connections in the human foetal brain," Acta Paediatr., vol. 99, no. 8, pp. 1119-1127, 2010.

[44] J. Kolasinski, E. Takahashi, A. A. Stevens, T. Benner, B. Fischl, L. Zöllei, and P. E. Grant, "Radial and tangential neuronal migration pathways in the human fetal brain: anatomically distinct patterns of diffusion MRI coherence," Neuroimage, vol. 79, pp. 412-422, Oct. 2013.

[45] E. Takahashi, R. D. Folkerth, A. M. Galaburda, and P. E. Grant, "Emerging Cerebral Connectivity in the Human Fetal Brain: An MR Tractography Study," Cereb. Cortex, vol. 22, no. 2, pp. 455-464, Feb. 2012.

[46] E. Takahashi, E. Hayashi, J. D. Schmahmann, and P. E. Grant, "Development of cerebellar connectivity in human fetal brains revealed by high angular resolution diffusion tractography," Neuroimage, vol. 96, pp. 326-333, Aug. 2014.

[47] C. Mitter, D. Prayer, P. C. Brugger, M. Weber, and G. Kasprian, "In Vivo Tractography of Fetal Association Fibers," PLoS One, vol. 10, no. 3, Mar. 2015.

[48] D. C. Van Essen, "A tension-based theory of morphogenesis and compact wiring in the central nervous system," Nature, vol. 385, no. 6614, pp. 313-318, Jan. 1997.

[49] C. C. Hilgetag and H. Barbas, "Developmental mechanics of the primate cerebral cortex," Anat. Embryol. (Berl)., vol. 210, no. 5-6, pp. 411-417, Dec. 2005.

[50] G. Xu, A. K. Knutsen, K. Dikranian, C. D. Kroenke, P. V Bayly, and L. A. Taber, "Axons pull on the brain, but tension does not drive cortical folding.," J. Biomech. Eng., vol. 132, no. 7, p. 071013, Jul. 2010.

[51] L. Ronan, N. Voets, C. Rua, A. Alexander-Bloch, M. Hough, C. Mackay, T. J. Crow, A. James, J. N. Giedd, and P. C. Fletcher, "Differential Tangential Expansion as a Mechanism for Cortical Gyrification.," Cereb. Cortex, pp. 1-10, Mar. 2013.

[52] A. C. Evans, "Networks of anatomical covariance," Neuroimage, vol. 80, pp. 489-504, Oct. 2013.

This article is protected by copyright. All rights reserved. 
[53] G. Ball, J. P. Boardman, D. Rueckert, P. Aljabar, T. Arichi, N. Merchant, I. S. Gousias, a D. Edwards, and S. J. Counsell, "The Effect of Preterm Birth on Thalamic and Cortical Development.," Cereb. Cortex, pp. 1-9, Jul. 2011.

[54] J. S. Poh, Y. Li, N. Ratnarajah, M. V. Fortier, Y. S. Chong, K. Kwek, S.-M. Saw, P. D. Gluckman, M. J. Meaney, and A. Qiu, "Developmental synchrony of thalamocortical circuits in the neonatal brain," Neuroimage.

[55] A. Melbourne, G. S. Kendall, M. J. Cardoso, R. Gunny, N. J. Robertson, N. Marlow, and S. Ourselin, "Preterm birth affects the developmental synergy between cortical folding and cortical connectivity observed on multimodal MRI," Neuroimage, vol. 89, pp. 23-34, Apr. 2014.

[56] G. E. Alexander, M. R. DeLong, and P. L. Strick, "Parallel Organization of Functionally Segregated Circuits Linking Basal Ganglia and Cortex," Annu. Rev. Neurosci., vol. 9, no. 1, pp. 357-381, 1986.

[57] D. C. Van Essen, "Corticocortical and thalamocortical information flow in the primate visual system,” Prog. Brain Res., vol. 149, pp. 173-185, 2005.

[58] J. L. Cummings, "Anatomic and behavioral aspects of frontal-subcortical circuits," Ann. N. Y. Acad. Sci., vol. 769, pp. 1-13, Dec. 1995.

[59] G. Ball, L. Pazderova, A. Chew, N. Tusor, N. Merchant, T. Arichi, J. M. Allsop, F. M. Cowan, A. D. Edwards, and S. J. Counsell, "Thalamocortical Connectivity Predicts Cognition in Children Born Preterm," Cereb. Cortex (New York, N.Y. 1991), Jan. 2015.

[60] L. Penke, S. M. Maniega, M. E. Bastin, M. C. Valdés Hernández, C. Murray, N. A. Royle, J. M. Starr, J. M. Wardlaw, and I. J. Deary, "Brain white matter tract integrity as a neural foundation for general intelligence," Mol. Psychiatry, vol. 17, no. 10, pp. 1026-1030, Oct. 2012.

[61] M. Rubinov and O. Sporns, "Complex network measures of brain connectivity: uses and interpretations," Neuroimage, vol. 52, no. 3, pp. 1059-1069, Sep. 2010.

[62] M. P. van den Heuvel and O. Sporns, "Rich-club organization of the human connectome," J. Neurosci. Off. J. Soc. Neurosci., vol. 31, no. 44, pp. 15775-15786, Nov. 2011.

[63] M. Senden, G. Deco, M. A. de Reus, R. Goebel, and M. P. van den Heuvel, "Rich club organization supports a diverse set of functional network configurations," Neuroimage, vol. 96, pp. 174-182, Aug. 2014.

[64] M. P. van den Heuvel, R. S. Kahn, J. Goñi, and O. Sporns, "High-cost, high-capacity backbone for global brain communication," Proc. Natl. Acad. Sci. U. S. A., vol. 109, no. 28 , pp. 11372-11377, Jul. 2012.

[65] G. Ball, P. Aljabar, S. Zebari, N. Tusor, T. Arichi, N. Merchant, E. C. Robinson, E. Ogundipe, D. Rueckert, A. D. Edwards, and S. J. Counsell, "Rich-club organization of the newborn human brain.," Proc. Natl. Acad. Sci. U. S. A., vol. 111, no. 20, pp. 745661, May 2014.

[66] M. P. van den Heuvel, K. J. Kersbergen, M. A. de Reus, K. Keunen, R. S. Kahn, F. Groenendaal, L. S. de Vries, and M. J. N. L. Benders, "The Neonatal Connectome During Preterm Brain Development," Cereb. Cortex, p. bhu095, May 2014.

[67] M. D. Fox and M. E. Raichle, "Spontaneous fluctuations in brain activity observed with functional magnetic resonance imaging.," Nat. Rev. Neurosci., vol. 8, no. 9, pp. 700-711, 2007.

This article is protected by copyright. All rights reserved. 
[68] M. D. Fox, A. Z. Snyder, J. L. Vincent, M. Corbetta, D. C. Van Essen, and M. E. Raichle, "The human brain is intrinsically organized into dynamic, anticorrelated functional networks.," Proc. Natl. Acad. Sci. U. S. A., vol. 102, no. 27, pp. 9673-9678, 2005.

[69] P. Fransson, B. Skiöld, S. Horsch, A. Nordell, M. Blennow, H. Lagercrantz, and U. Aden, "Resting-state networks in the infant brain.," Proc. Natl. Acad. Sci. U. S. A., vol. 104, no. 39, pp. 15531-6, Sep. 2007.

[70] E. Damaraju, A. Caprihan, J. R. R. Lowe, E. Allen, V. D. D. Calhoun, and J. P. P. Phillips, "Functional connectivity in the developing brain: a longitudinal study from 4 to 9months of age.," Neuroimage, vol. 84, no. 2014, pp. 169-80, Aug. 2013.

[71] E. Damaraju, J. R. Phillips, J. R. Lowe, R. Ohls, V. D. Calhoun, and A. Caprihan, "Resting-state functional connectivity differences in premature children.," Front. Syst. Neurosci., vol. 4, no. June, pp. 1-13, Jan. 2010.

[72] V. Doria, C. F. Beckmann, T. Arichi, N. Merchant, M. Groppo, F. E. Turkheimer, S. J. Counsell, M. Murgasova, P. Aljabar, R. G. Nunes, D. J. Larkman, G. Rees, and a D. Edwards, "Emergence of resting state networks in the preterm human brain.," Proc. Natl. Acad. Sci. U. S. A., vol. 107, no. 46, pp. 20015-20, Nov. 2010.

[73] P. Fransson, U. Aden, M. Blennow, and H. Lagercrantz, "The functional architecture of the infant brain as revealed by resting-state fMRI.," Cereb. Cortex, vol. 21, no. 1, pp. 145-54, Jan. 2011.

[74] P. Fransson, B. Skiöld, M. Engström, B. Hallberg, M. Mosskin, U. Aden, H. Lagercrantz, and M. Blennow, "Spontaneous brain activity in the newborn brain during natural sleep--an fMRI study in infants born at full term.," Pediatr. Res., vol. 66, no. 3, pp. 301-5, Sep. 2009.

[75] W. Gao, S. Alcauter, A. Elton, C. R. Hernandez-Castillo, J. K. Smith, J. Ramirez, and W. Lin, "Functional Network Development During the First Year: Relative Sequence and Socioeconomic Correlations.," Cereb. Cortex, pp. 1-10, May 2014.

[76] W. Gao, S. Alcauter, J. K. Smith, J. H. Gilmore, and W. Lin, "Development of human brain cortical network architecture during infancy.," Brain Struct. Funct., Jan. 2014.

[77] W. Gao, A. Elton, H. Zhu, S. Alcauter, J. K. Smith, J. H. Gilmore, and W. Lin, "Intersubject Variability of and Genetic Effects on the Brain's Functional Connectivity during Infancy.," J. Neurosci., vol. 34, no. 34, pp. 11288-96, 2014.

[78] W. Gao, J. H. Gilmore, K. S. Giovanello, J. K. Smith, D. Shen, H. Zhu, and W. Lin, "Temporal and spatial evolution of brain network topology during the first two years of life," PLoS One, vol. 6, no. 9, 2011.

[79] W. Gao, J. H. Gilmore, D. Shen, J. K. Smith, H. Zhu, and W. Lin, “The synchronization within and interaction between the default and dorsal attention networks in early infancy," Cereb. Cortex, vol. 23, no. 3, pp. 594-603, 2013.

[80] W. Gao, H. Zhu, K. S. Giovanello, J. K. Smith, D. Shen, J. H. Gilmore, and W. Lin, "Evidence on the emergence of the brain's default network from 2-week-old to 2-yearold healthy pediatric subjects.," Proceedings of the National Academy of Sciences of the United States of America, vol. 106, no. 16. pp. 6790-5, 21-May-2009.

[81] W. Lin, Q. Zhu, W. Gao, Y. Chen, C.-H. Toh, M. Styner, G. Gerig, J. K. Smith, B. Biswal, and J. H. Gilmore, "Functional connectivity MR imaging reveals cortical functional connectivity in the developing brain.," AJNR. Am. J. Neuroradiol., vol. 29,

This article is protected by copyright. All rights reserved. 
no. 10, pp. 1883-9, Nov. 2008.

[82] D. Perani, M. C. Saccuman, P. Scifo, A. Anwander, A. Awander, D. Spada, C. Baldoli, A. Poloniato, G. Lohmann, and A. D. Friederici, "Neural language networks at birth," Proc. Natl. Acad. Sci., vol. 108, no. 38, pp. 1-6, Sep. 2011.

[83] C. D. Smyser, T. E. Inder, J. S. Shimony, J. E. Hill, A. J. Degnan, A. Z. Snyder, and J. J. Neil, "Longitudinal Analysis of Neural Network Development in Preterm Infants," Cereb. Cortex, vol. 20, no. December, pp. 2852-2862, 2010.

[84] C. D. Smyser, A. Z. Snyder, J. S. Shimony, T. M. Blazey, T. E. Inder, and J. J. Neil, "Effects of White Matter Injury on Resting State fMRI Measures in Prematurely Born Infants,"PLoS One, vol. 8, no. 7, p. e68098, Jul. 2013.

[85] C. D. Smyser, A. Z. Snyder, J. S. Shimony, A. Mitra, T. E. Inder, and J. J. Neil, "Resting-State Network Complexity and Magnitude Are Reduced in Prematurely Born Infants.," Cereb. Cortex, pp. 1-12, Oct. 2014.

[86] S. Alcauter, W. Lin, J. K. Smith, S. J. Short, B. D. Goldman, J. S. Reznick, J. H. Gilmore, and W. Gao, "Development of Thalamocortical Connectivity during Infancy and Its Cognitive Correlations.," J. Neurosci., vol. 34, no. 27, pp. 9067-75, 2014.

[87] S. Alcauter, W. Lin, J. K. Smith, S. J. Short, B. D. Goldman, J. S. Reznick, J. H. Gilmore, and W. Gao, "Development of Thalamocortical Connectivity during Infancy and Its Cognitive Correlations.," J. Neurosci., vol. 34, no. 27, pp. 9067-75, 2014.

[88] S. Alcauter, W. Lin, J. K. Smith, B. D. Goldman, J. S. Reznick, J. H. Gilmore, and W. Gao, "Frequency of spontaneous BOLD signal shifts during infancy and correlates with cognitive performance.," Dev. Cogn. Neurosci., vol. 12, pp. 40-50, Apr. 2015.

[89] M. E. Thomason, M. T. Dassanayake, S. Shen, Y. Katkuri, M. Alexis, A. L. Anderson, L. Yeo, S. Mody, E. Hernandez-Andrade, S. S. Hassan, C. Studholme, J.-W. Jeong, and R. Romero, "Cross-hemispheric functional connectivity in the human fetal brain.," Sci. Transl. Med., vol. 5, no. 173, p. 173ra24, Feb. 2013.

[90] M. E. Thomason, L. E. Grove, T. A. Lozon, A. M. Vila, Y. Ye, M. J. Nye, J. H. Manning, A. Pappas, E. Hernandez-Andrade, L. Yeo, S. Mody, S. Berman, S. S. Hassan, and R. Romero, "Age-related increases in long-range connectivity in fetal functional neural connectivity networks in utero.," Dev. Cogn. Neurosci., Sep. 2014.

[91] S. Vanhatalo, J. Matias Palva, S. Andersson, C. Rivera, J. Voipio, and K. Kaila, "Slow endogenous activity transients and developmental expression of $\mathrm{K}+-\mathrm{Cl}$ - cotransporter 2 in the immature human cortex," Eur. J. Neurosci., vol. 22, no. 11, pp. 2799-2804, 2005.

[92] S. Vanhatalo and K. Kaila, "Development of neonatal EEG activity: From phenomenology to physiology," Semin. Fetal Neonatal Med., vol. 11, no. 6, pp. 471478, 2006.

[93] O. Räsänen, M. Metsäranta, and S. Vanhatalo, "Development of a novel robust measure for interhemispheric synchrony in the neonatal EEG: Activation Synchrony Index (ASI)," Neuroimage, vol. 69, pp. 256-266, 2013.

[94] A. Omidvarnia, P. Fransson, M. Metsäranta, and S. Vanhatalo, "Functional Bimodality in the Brain Networks of Preterm and Term Human Newborns.," Cereb. Cortex, no. October, pp. 1-12, 2013.

[95] M. Colonnese and R. Khazipov, "Spontaneous activity in developing sensory circuits: Implications for resting state fMRI.," Neuroimage, Feb. 2012.

This article is protected by copyright. All rights reserved. 
[96] J. Elman, E. Bates, and M. Johnson, "Rethinking innateness," 1996.

[97] E. Lenneberg, N. Chomsky, and O. Marx, Biological foundations of language. 1967.

[98] G. Dehaene-Lambertz, S. Dehaene, and L. Hertz-Pannier, "Functional neuroimaging of speech perception in infants.," Science, vol. 298, no. 5600, pp. 2013-5, Dec. 2002.

[99] G. Dehaene-Lambertz, L. Hertz-Pannier, J. Dubois, S. Mériaux, A. Roche, M. Sigman, and S. Dehaene, "Functional organization of perisylvian activation during presentation of sentences in preverbal infants.," Proc. Natl. Acad. Sci. U. S. A., vol. 103, no. 38, pp. 14240-14245, Sep. 2006.

[100] G. Dehaene-Lambertz, A. Montavont, A. Jobert, L. Allirol, J. Dubois, L. HertzPannier, and S. Dehaene, "Language or music, mother or Mozart? Structural and environmental influences on infants' language networks.," Brain Lang., vol. 114, no. 2, pp. 53-65, Aug. 2010.

[101] M. Peña, A. Maki, D. Kovačić, G. Dehaene-Lambertz, H. Koizumi, F. Bouquet, and J. Mehler, "Sounds and silence : An optical topography study of language recognition at birth," Proc. Natl. Acad. Sci. U. S. A., vol. 100, no. 20, pp. 11702-11705, 2003.

[102] D. Perani, M. C. Saccuman, P. Scifo, D. Spada, G. Andreolli, R. Rovelli, C. Baldoli, and S. Koelsch, "Functional specializations for music processing in the human newborn brain.," Proc. Natl. Acad. Sci. U. S. A., vol. 107, no. 10, pp. 4758-63, Mar. 2010.

[103] S. Telkemeyer, S. Rossi, S. P. Koch, T. Nierhaus, J. Steinbrink, D. Poeppel, H. Obrig, and I. Wartenburger, "Sensitivity of newborn auditory cortex to the temporal structure of sounds.," J. Neurosci., vol. 29, no. 47, pp. 14726-33, Nov. 2009.

[104] I. Wartenburger, J. Steinbrink, S. Telkemeyer, M. Friedrich, A. D. Friederici, and H. Obrig, "The processing of prosody: Evidence of interhemispheric specialization at the age of four," Neuroimage, vol. 34, no. 1, pp. 416-425, 2007.

[105] D. Bristow, G. Dehaene-Lambertz, J. Mattout, C. Soares, T. Gliga, S. Baillet, and J.-F. Mangin, "Hearing faces: how the infant brain matches the face it sees with the speech it hears.," J. Cogn. Neurosci., vol. 21, no. 5, pp. 905-21, May 2009.

[106] M. Mahmoudzadeh, G. Dehaene-Lambertz, M. Fournier, G. Kongolo, S. Goudjil, J. Dubois, R. Grebe, and F. Wallois, "Syllabic discrimination in premature human infants prior to complete formation of cortical layers," Proc. Natl. Acad. Sci., vol. 110, no. 12, pp. 1-6, Mar. 2013.

[107] V. Izard, G. Dehaene-Lambertz, and S. Dehaene, "Distinct cerebral pathways for object identity and number in human infants," PLoS Biol., vol. 6, no. 2, pp. 02750285, 2008.

[108] M. Roy, D. Shohamy, and T. D. Wager, "Ventromedial prefrontal-subcortical systems and the generation of affective meaning," Trends Cogn. Sci., vol. 16, no. 3, pp. 147$156,2012$.

[109] J. B. Tenenbaum, C. Kemp, T. L. Griffiths, and N. D. Goodman, "How to grow a mind: statistics, structure, and abstraction.," Science, vol. 331, no. 6022, pp. 12791285, 2011.

[110] R. Draganova, H. Eswaran, P. Murphy, M. Huotilainen, C. Lowery, and H. Preissl, "Sound frequency change detection in fetuses and newborns, a magnetoencephalographic study," Neuroimage, vol. 28, no. 2, pp. 354-361, 2005.

This article is protected by copyright. All rights reserved. 
[111] H. Eswaran, C. L. Lowery, J. D. Wilson, P. Murphy, and H. Preissl, "Functional development of the visual system in human fetus using magnetoencephalography," Exp. Neurol., vol. 190, no. SUPPL. 1, pp. 52-58, 2004.

[112] M. Huotilainen, A. Kujala, M. Hotakainen, L. Parkkonen, S. Taulu, J. Simola, J. Nenonen, M. Karjalainen, and R. Näätänen, "Short-term memory functions of the human fetus recorded with magnetoencephalography.," Neuroreport, vol. 16, no. 1, pp. 81-84, 2005.

[113] J. Muenssinger, T. Matuz, F. Schleger, I. Kiefer-Schmidt, R. Goelz, A. WackerGussmann, N. Birbaumer, and H. Preissl, "Auditory habituation in the fetus and neonate: An fMEG study,” Dev. Sci., vol. 16, no. 2, pp. 287-295, 2013.

[114] J. J. Rotteyeel, R. de Graaf, D. F. Stegeman, E. J. Colon, and Y. M. Visco, “The maturation of the central auditory conduction in preterm infants until three months post term. V. The auditory cortical response (ACR).," Hear. Res., vol. 27, no. 1, pp. 95110,1987

[115] L. Weitzman, L. Graziani, and L. Duhamel, "Maturation and topography of the auditory eyoked response of the prematurely born infant.," Electroencephalogr. Clin. Neurophysiol., vol. 23, no. 1, pp. 82-83, 1967.

[116] T. Arichi, A. Moraux, A. Melendez, V. Doria, M. Groppo, N. Merchant, S. Combs, E. Burdet, D. J. Larkman, S. J. Counsell, C. F. Beckmann, and a D. Edwards, "Somatosensory cortical activation identified by functional MRI in preterm and term infants.," Neuroimage, vol. 49, no. 3, pp. 2063-71, Feb. 2010.

[117] R. Jardri, D. Pins, V. Houfflin-Debarge, C. Chaffiotte, N. Rocourt, J.-P. Pruvo, M. Steinling, P. Delion, and P. Thomas, "Fetal cortical activation to sound at 33 weeks of gestation: a functional MRI study.," Neuroimage, vol. 42, no. 1, pp. 10-8, Aug. 2008.

[118] M. Peña, E. Pittaluga, and J. Mehler, "Language acquisition in premature and full-term infants.," Proc. Natl. Acad. Sci. U. S. A., vol. 107, no. 8, pp. 3823-3828, 2010.

[119] M. Pena, J. F. Werker, and G. Dehaene-Lambertz, "Earlier Speech Exposure Does Not Accelerate Speech Acquisition," J. Neurosci., vol. 32, no. 33, pp. 11159-11163, 2012.

[120] T. R. Barkat, D. B. Polley, and T. K. Hensch, "A critical period for auditory thalamocortical connectivity.," Nat. Neurosci., vol. 14, no. 9, pp. 1189-94, Sep. 2011.

[121] T. K. Hensch, “Critical period regulation.," Annu. Rev. Neurosci., vol. 27, pp. 549$579,2004$.

[122] G. Jando, E. Miko-Barath, K. Marko, K. Hollody, B. Torok, and I. Kovacs, "Earlyonset binocularity in preterm infants reveals experience-dependent visual development in humans," Proc. Natl. Acad. Sci., vol. 109, no. 27, pp. 11049-11052, 2012.

[123] M. Peña, D. Arias, and G. Dehaene-Lambertz, "Gaze Following Is Accelerated in Healthy Preterm Infants.," Psychol. Sci., no. August, 2014.

[124] N. Gonzalez-Gomez and T. Nazzi, "Phonotactic acquisition in healthy preterm infants," Dev. Sci., vol. 15, no. 6, pp. 885-894, 2012.

[125] B. M. D’Onofrio, Q. a. Class, M. E. Rickert, H. Larsson, N. Långström, and P. Lichtenstein, "Preterm Birth and Mortality and Morbidity," JAMA Psychiatry, vol. 70, no. 11, p. 1231, 2013.

[126] J. Dubois, G. Dehaene-Lambertz, C. Soarès, Y. Cointepas, D. Le Bihan, and L. HertzPannier, "Microstructural correlates of infant functional development: example of the

This article is protected by copyright. All rights reserved. 
visual pathways," J. Neurosci. Off. J. Soc. Neurosci., vol. 28, no. 8, pp. 1943-1948, Feb. 2008.

[127] S. Kouider, C. Stahlhut, S. V Gelskov, L. S. Barbosa, M. Dutat, V. de Gardelle, A. Christophe, S. Dehaene, and G. Dehaene-Lambertz, "A neural marker of perceptual consciousness in infants.," Science, vol. 340, no. 6130, pp. 376-80, Apr. 2013.

[128] C. Nelson and R. deRegnier, "Neural correlates of attention and memory in the first year of life," Dev. Neuropsychol., 1992.

[129] K. Friston, “A theory of cortical responses.," Philos. Trans. R. Soc. Lond. B. Biol. Sci., vol. 360, no. 1456, pp. 815-836, 2005.

[130] E. A. Maylor and A. M. Wing, "Age Differences in Postural Stability are Increased by Additional Cognitive Demands," Journals Gerontol. Ser. B Psychol. Sci. Soc. Sci., vol. 51B, no. 3, pp. P143-P154, May 1996.

[131] D. Mareschal and M. H. Johnson, "The 'what' and 'where' of object representations in infancy," Cognition, vol. 88, no. 3, pp. 259-276, Jul. 2003.

[132] M. Nardini, R. Bedford, and D. Mareschal, "Fusion of visual cues is not mandatory in children.," Proc. Natl. Acad. Sci. U. S. A., vol. 107, no. 39, pp. 17041-17046, 2010.

[133] N. Kriegeskorte, R. Cusack, and P. Bandettini, "How does an fMRI voxel sample the neuronal activity pattern: compact-kernel or complex spatiotemporal filter?," Neuroimage, vol. 49, no. 3, pp. 1965-76, Feb. 2010.

[134] N. Kriegeskorte and P. Bandettini, "Combining the tools: Activation-and informationbased fMRI analysis," Neuroimage, vol. 38, no. 4, pp. 666-668, 2007.

[135] N. Kriegeskorte and R. A. Kievit, "Representational geometry: integrating cognition, computation, and the brain," Trends Cogn. Sci., vol. 17, no. 8, pp. 401-412, Aug. 2013.

[136] M. L. Krishnan, L. E. Dyet, J. P. Boardman, O. Kapellou, J. M. Allsop, F. Cowan, A. D. Edwards, M. A. Rutherford, and S. J. Counsell, "Relationship between white matter apparent diffusion coefficients in preterm infants at term-equivalent age and developmental outcome at 2 years.," Pediatrics, vol. 120, no. 3, pp. e604-9, Sep. 2007.

[137] S. J. Counsell, a D. Edwards, A. T. M. Chew, M. Anjari, L. E. Dyet, L. Srinivasan, J. P. Boardman, J. M. Allsop, J. V Hajnal, M. a Rutherford, and F. M. Cowan, "Specific relations between neurodevelopmental abilities and white matter microstructure in children born preterm.," Brain, vol. 131, no. Pt 12, pp. 3201-8, Dec. 2008.

[138] R. T. Constable, L. R. Ment, B. R. Vohr, S. R. Kesler, R. K. Fulbright, C. Lacadie, S. Delancy, K. H. Katz, K. C. Schneider, R. J. Schafer, R. W. Makuch, and A. R. Reiss, "Prematurely born children demonstrate white matter microstructural differences at 12 years of age, relative to term control subjects: an investigation of group and gender effects.," Pediatrics, vol. 121, no. 2, pp. 306-16, Mar. 2008.

[139] D. Kontis, M. Catani, M. Cuddy, and M. Walshe, "Diffusion tensor MRI of the corpus callosum and cognitive function in adults born preterm," ..., 2009.

[140] J. F. de Kieviet, D. J. Heslenfeld, P. J. W. Pouwels, H. N. Lafeber, R. J. Vermeulen, R. M. van Elburg, and J. Oosterlaan, "A crucial role for white matter alterations in interference control problems of very preterm children," Pediatr. Res., vol. 75, no. 6, pp. 731-737, 2014.

[141] Z. Nagy, H. Westerberg, and S. Skare, "Preterm children have disturbances of white

This article is protected by copyright. All rights reserved. 
matter at 11 years of age as shown by diffusion tensor imaging," Pediatr. ..., 2003.

[142] R. Rathbone, S. Counsell, and O. Kapellou, "Perinatal cortical growth and childhood neurocognitive abilities," Neurology, 2011.

[143] T. Inder, P. Huppi, and S. Warfield, "Periventricular white matter injury in the premature infant is followed by reduced cerebral cortical gray matter volume at term," Ann. ..., 1999.

[144] T. E. Inder, S. K. Warfield, H. Wang, P. S. Hüppi, and J. J. Volpe, “Abnormal cerebral structure is present at term in premature infants.," Pediatrics, vol. 115, no. 2, pp. 28694, Feb. 2005.

[145] B. S. Peterson, A. W. Anderson, R. Ehrenkranz, L. H. Staib, M. Tageldin, E. Colson, J. C. Gore, C. C. Duncan, R. Makuch, and L. R. Ment, "Regional brain volumes and their later neurodevelopmental correlates in term and preterm infants.," Pediatrics, vol. 111, no. 5 Pt 1, pp. 939-948, 2003.

[146] J. P. Boardman, C. Craven, S. Valappil, S. J. Counsell, L. E. Dyet, D. Rueckert, P. Aljabar, M. a Rutherford, a T. M. Chew, J. M. Allsop, F. Cowan, and a D. Edwards, "A common neonatal image phenotype predicts adverse neurodevelopmental outcome in children born preterm.," Neuroimage, vol. 52, no. 2, pp. 409-14, Aug. 2010.

[147] G. Ball, L. Pazderova, A. Chew, N. Tusor, N. Merchant, T. Arichi, J. M. Allsop, F. M. Cowan, a D. Edwards, and S. J. Counsell, "Thalamocortical Connectivity Predicts Cognition in Children Born Preterm.," Cereb. Cortex, pp. 1-9, Jan. 2015.

[148] L. Bassi, D. Ricci, A. Volzone, J. M. Allsop, L. Srinivasan, A. Pai, C. Ribes, L. A. Ramenghi, E. Mercuri, F. Mosca, A. D. Edwards, F. M. Cowan, M. A. Rutherford, and S. J. Counsell, "Probabilistic diffusion tractography of the optic radiations and visual function in preterm infants at term equivalent age," Brain, vol. 131, no. Pt 2, pp. 573$582,2008$.

[149] M. Groppo, D. Ricci, L. Bassi, N. Merchant, V. Doria, T. Arichi, J. M. Allsop, L. Ramenghi, M. J. Fox, F. M. Cowan, S. J. Counsell, and A. D. Edwards, "Development of the optic radiations and visual function after premature birth," Cortex, vol. 10.1016/j., 2012.

[150] E. Redcay and J. Moran, "Intrinsic functional network organization in highfunctioning adolescents with autism spectrum disorder," Front. Hum. ..., 2013.

[151] D. Fair, J. Posner, B. Nagel, and D. Bathula, “Atypical default network connectivity in youth with attention-deficit/hyperactivity disorder," Biol. ..., 2010.

[152] R. T. Constable, B. R. Vohr, D. Scheinost, J. R. Benjamin, R. K. Fulbright, C. Lacadie, K. C. Schneider, K. H. Katz, H. Zhang, X. Papademetris, and L. R. Ment, "A left cerebellar pathway mediates language in prematurely-born young adults.," Neuroimage, vol. 64, pp. 371-8, Jan. 2013.

[153] T. P. White, I. Symington, N. P. Castellanos, P. J. Brittain, S. Froudist Walsh, K.-W. Nam, J. R. Sato, M. P. G. Allin, S. S. Shergill, R. M. Murray, S. C. R. Williams, and C. Nosarti, "Dysconnectivity of neurocognitive networks at rest in very-preterm born adults.,"NeuroImage. Clin., vol. 4, no. 2014, pp. 352-65, Jan. 2014.

[154] A. P. Salzwedel, K. M. Grewen, C. Vachet, G. Gerig, W. Lin, and W. Gao, "Prenatal drug exposure affects neonatal brain functional connectivity.," J. Neurosci., vol. 35, no. 14, pp. 5860-9, Apr. 2015.

[155] J. D. Power, K. A. Barnes, A. Z. Snyder, B. L. Schlaggar, and S. E. Petersen,

This article is protected by copyright. All rights reserved. 
"Spurious but systematic correlations in functional connectivity MRI networks arise from subject motion," Neuroimage, vol. 59, no. 3, pp. 2142-2154, Oct. 2011.

[156] J. D. Power, A. Mitra, T. O. Laumann, A. Z. Snyder, B. L. Schlaggar, and S. E. Petersen, "Methods to detect, characterize, and remove motion artifact in resting state fMRI," Neuroimage, vol. 84, pp. 320-341, 2014.

[157] J. D. Power, B. L. Schlaggar, and S. E. Petersen, "Recent progress and outstanding issues in motion correction in resting state fMRI," Neuroimage, vol. 105, pp. 536-551, 2015.

[158] M. D. Greicius, V. Kiviniemi, O. Tervonen, V. Vainionpää, A. L. Reiss, and V. Menon, "Persistent Default- Mode Network Connectivity During Light Sedation," Hum. Brain Mapp., vol. 29, no. 7, pp. 839-847, 2008.

[159] E. a. Stamatakis, R. M. Adapa, A. R. Absalom, and D. K. Menon, "Changes in resting neural connectivity during propofol sedation," PLoS One, vol. 5, no. 12, 2010.

[160] J. L. Vincent, G. H. Patel, M. D. Fox, a Z. Snyder, J. T. Baker, D. C. Van Essen, J. M. Zempel, L. H. Snyder, M. Corbetta, and M. E. Raichle, "Intrinsic functional architecture in the anaesthetized monkey brain.," Nature, vol. 447, no. 7140, pp. 8386, 2007.

[161] J. Duyn, "Spontaneous fMRI activity during resting wakefulness and sleep," in Progress in Brain Research, 2011, pp. 295-305.

[162] M. Fukunaga, S. G. Horovitz, P. van Gelderen, J. a. de Zwart, J. M. Jansma, V. N. Ikonomidou, R. Chu, R. H. R. Deckers, D. a. Leopold, and J. H. Duyn, "Largeamplitude, spatially correlated fluctuations in BOLD fMRI signals during extended rest and early sleep stages," Magn. Reson. Imaging, vol. 24, no. 8, pp. 979-992, 2006.

[163] S. G. Horovitz, A. R. Braun, W. S. Carr, D. Picchioni, T. J. Balkin, M. Fukunaga, and J. H. Duyn, "Decoupling of the brain's default mode network during deep sleep.," Proc. Natl. Acad. Sci. U. S. A., vol. 106, no. 27, pp. 11376-11381, 2009.

[164] S. Vanhatalo, A. Alnajjar, V. T. Nguyen, P. Colditz, and P. Fransson, "Safety of EEGfMRI recordings in newborn infants at 3T: a study using a baby-size phantom.," Clin. Neurophysiol., vol. 125, no. 5, pp. 941-6, May 2014.

[165] C. E. Sanchez, J. E. Richards, and C. R. Almli, "Neurodevelopmental MRI brain templates for children from 2 weeks to 4 years of age.," Dev. Psychobiol., Jun. 2011.

[166] T. Arichi, G. Fagiolo, M. Varela, A. Melendez-Calderon, A. Allievi, N. Merchant, N. Tusor, S. J. Counsell, E. Burdet, C. F. Beckmann, and a D. Edwards, "Development of BOLD signal Hemodynamic Responses in the Human Brain.," Neuroimage, vol. 63, no. 2, pp. 663-73, Jul. 2012.

[167] R. Cusack, C. J. Wild, A. C. Linke, T. Arichi, D. S. C. Lee, and V. K. Han, "Optimizing stimulation and analysis protocols for neonatal fMRI," PLoS One.

[168] Kabdebon, C., Leroy, F., Simmonet, H., Perrot, M., Dubois, J., \& Dehaene-Lambertz, G. (2014). Anatomical correlations of the international 10-20 sensor placement system in infants. "Neuroimage, 99, 342-356.

[169] Keil, B., Alagappan, V., Mareyam, A., McNab, J. A., Fujimoto, K., Tountcheva, V., Triantafyllou, C., Dilks, D. D., Kanwisher, N., Lin, W., Grant, P. E., \& Wald, L. L. (2011). Size-optimized 32-channel brain arrays for 3 T pediatric imaging. Magn Reson Med, 66(6), 1777-1787.

This article is protected by copyright. All rights reserved. 
Figure legends

Figure 1. Group mean rs-fMRI correlation maps demonstrating canonical resting-state networks in 25 healthy, term-born infants (mean gestational age at birth 39.4 weeks; mean postmenstrual age at scan 39.5 weeks). Depicted are medial and lateral views of the (A) somatomotor network generated using a left motor cortex seed, (B) visual network generated using a left visual cortex seed. And $(\mathrm{C})$ default mode network generated using a posterior cingulate cortex seed. The illustrated quantity is the Fisher Z-transformed correlation coefficient $(\mathrm{z}(\mathrm{r}))$, averaged over subjects; color threshold $(\mathrm{z}(\mathrm{r}))>0.18$. Results are overlaid on a neonate-specific mid-cortical surface reconstruction.

Figure 2. Group mean covariance matrices generated using 1065 cortical gray matter regions of interest. The block structure corresponds to RSNs to which each region is assigned, including the dorsal attention (DAN), ventral attention (VAN), somatomotor (SMN), visual (VIS), frontoparietal control (FPC), language (LAN), and default mode (DMN) networks. (A) Term infants; (B) preterm infants at term equivalent PMA. Note similarity of block structure in (A) and (B). This similarity reflects downscaling of positive and negative rs-fMRI covariance values in the preterm subjects relative to the term subjects. Figure provided courtesy of Anish Mitra.

Figure 3. Boxplot of 2.5-month-old infants' activations averaged over the left (red box) and right (green box) planum temporale for speech (mother's voice and an unknown mother's voice) and music (Mozart's piano sonata). The activation is significantly larger for speech in the left than the right planum. It is not the case for music. ${ }^{100}$

Figure 4. FMRI activation to the mother's voice (top) and to an unknown mother (bottom) in 2- to 3-month-old postterm infants projected on a 3D reconstruction of an individual infant. ${ }^{100}$ The mother's voice amplifies the response in the posterior temporal region and the median prefrontal region, whereas the response is decreased relative to the unknown voice in the orbitofrontal cortex, amygdala, and putamen. ${ }^{100}$

Figure 5. Responses to a change of voice and a change of phoneme measured with NIRS in 30 weeks gestation preterm neonates projected on a 3D reconstruction of an individual preterm brain. ${ }^{106}$ Speech syllables strongly activate the perisylvian regions from the temporal until the frontal areas with, in general, larger response in the right hemisphere, except in the posterior temporal region, in which the responses are faster and more prolonged on the left than on the right. The left inferior frontal region reacts only to a change of phoneme, whereas the right responds to change of phoneme and a change of voice. ${ }^{36}$

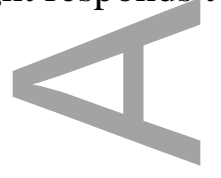

This article is protected by copyright. All rights reserved. 


\section{Box 1. Challenges and technical developments in infant neuroimaging $M R I$}

Scanning hardware. Smaller coils tailored to the infant head can provide higher signal-to-noise ratios, ${ }^{169}$ particularly for premature infants.

Hearing protection. It is important to protect infants from acoustic noise. Earplugs are helpful, although it can be difficult to keep them inserted in small ear canals. Ear defenders can be easier to use, although they may not fit in small head coils. Newer scanners and tailored scanning sequences can also reduce noise.

Motion. Subject motion remains a prevalent issue. Infants move with a different spatial and temporal pattern of movement to adults (Cusack et al, submitted). The degree and pattern of motion can contaminate estimates of resting state connectivity in particular, artificially enhancing connections between anatomically approximate regions while diminishing connections between regions further apart (especially anterior-posterior connections due to pitch movement). As an additional confound, regions laterally oriented to one another demonstrate greater correlation increases due to motion than other orientations. This has necessitated the advent of motion-correction procedures (i.e., "scrubbing"), which reduce this source of colored noise. ${ }^{155-157}$ Concerns regarding subject motion during acquisition have also led to infants being sedated for studies. ${ }^{69,72}$ While resting-state networks can be detected in sedated subjects, use of these medications affects measurements and limits comparability ${ }^{158-160}$ and is incompatible with cognitive studies.

In infants less than a few months of age, motion can be reduced using a swaddling vacuum-restraint cushion (http://cfimedical.com/medvac/). Older infants, however, do not like 

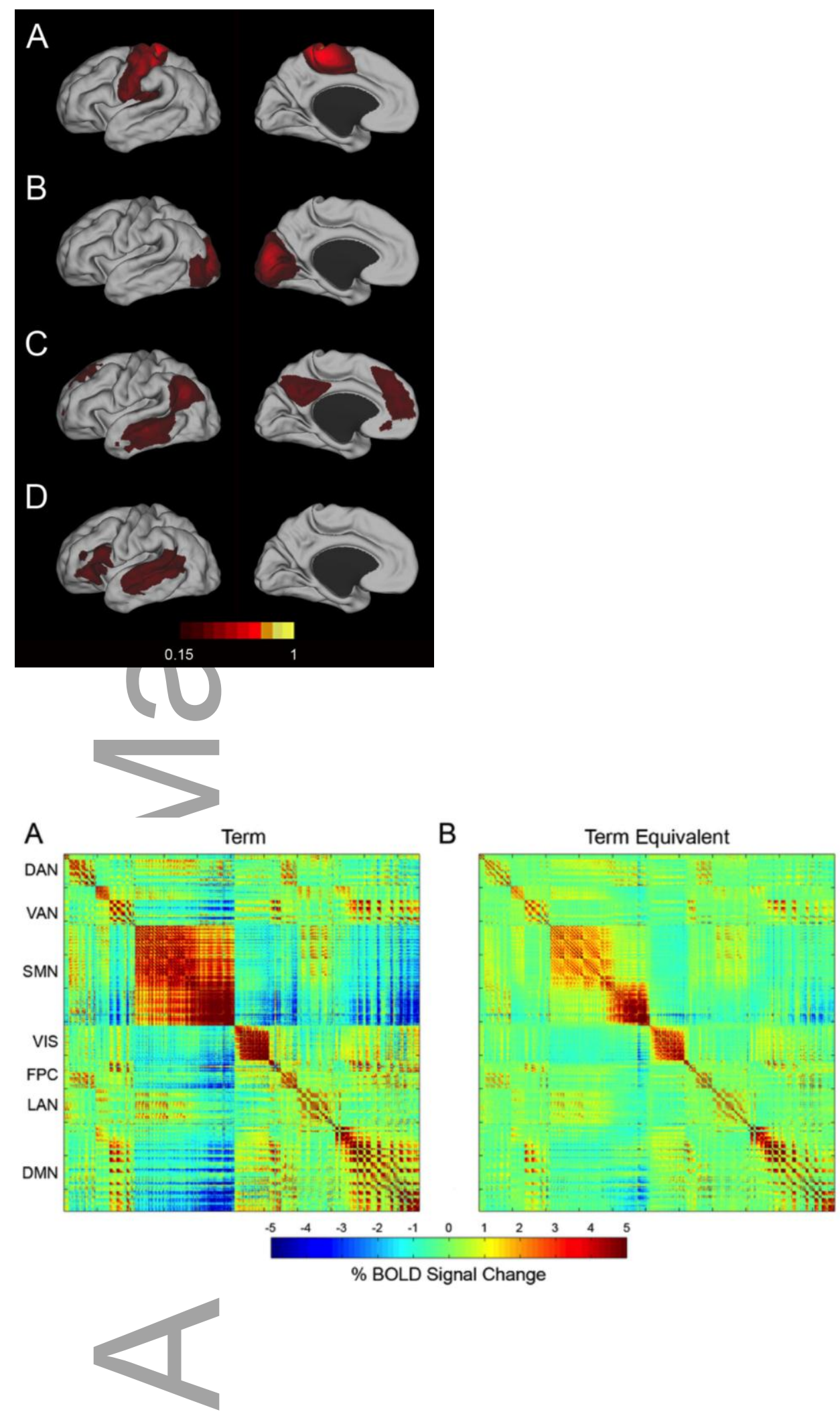

This article is protected by copyright. All rights reserved. 
The Emergence of Cognition
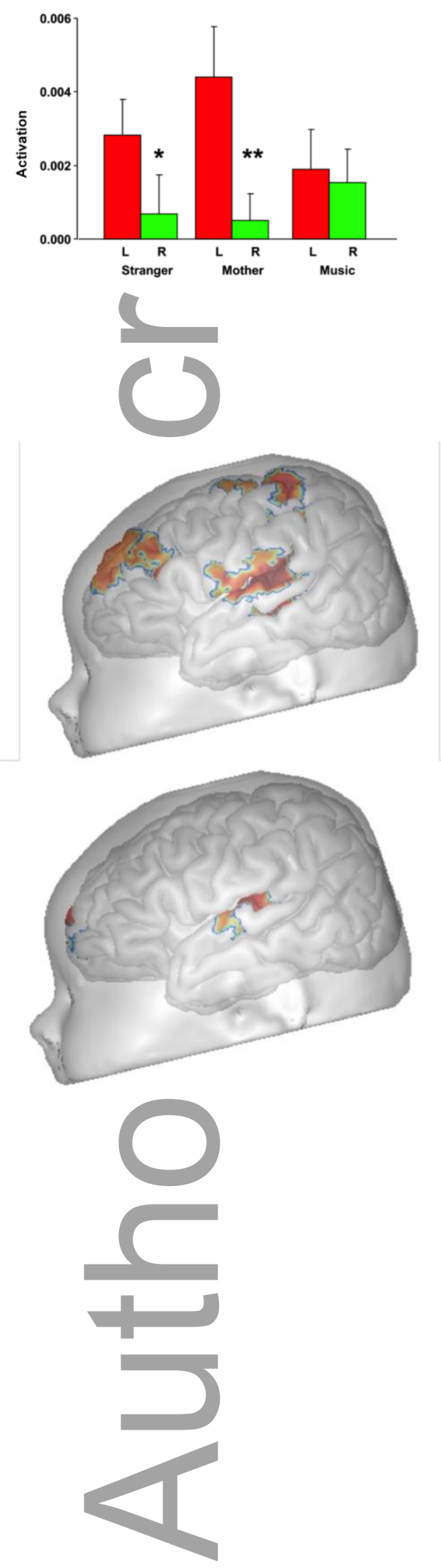

This article is protected by copyright. All rights reserved. 


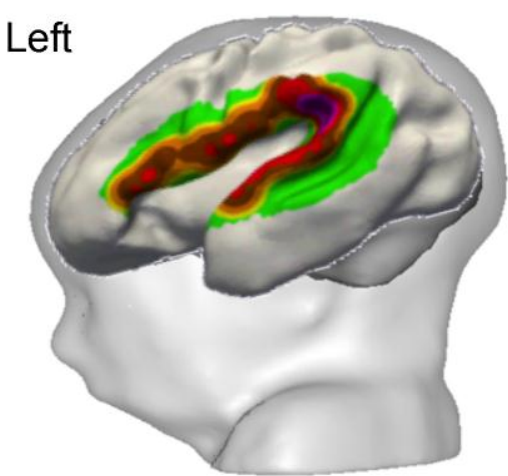

Phoneme change

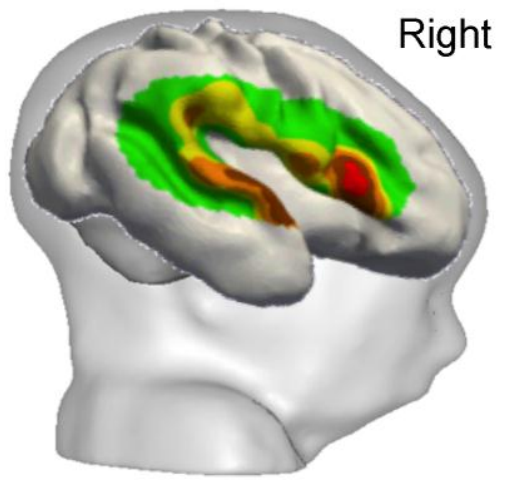

Voice change

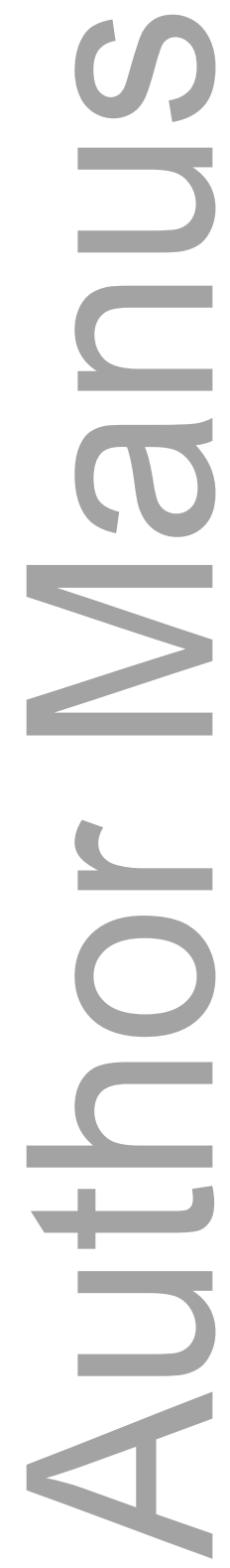

This article is protected by copyright. All rights reserved. 


\section{University Library}

\section{- M M I E E R VA A gateway to Melbourne's research publications}

Minerva Access is the Institutional Repository of The University of Melbourne

Author/s:

Cusack, R;Ball, G;Smyser, CD;Dehaene-Lambertz, G

Title:

A neural window on the emergence of cognition

Date:

2016-01-01

Citation:

Cusack, R., Ball, G., Smyser, C. D. \& Dehaene-Lambertz, G. (2016). A neural window on the emergence of cognition. YEAR IN COGNITIVE NEUROSCIENCE, 1369 (1), pp.7-23. https:// doi.org/10.1111/nyas.13036.

Persistent Link:

http://hdl.handle.net/11343/290786 